\title{
Hydrological extremes in the Aksu-Tarim River Basin: Mid-latitude dynamics
}

\author{
Hartmut Borth $^{2} \cdot$ Hui Tao ${ }^{1} \cdot$ Klaus Fraedrich $^{3} \cdot$ Andrea Schneidereit $^{4} \cdot$ Xiuhua Zhu $^{2}$
}

Received: 11 July 2014 / Accepted: 4 May 2015 / Published online: 25 June 2015

(C) The Author(s) 2015. This article is published with open access at Springerlink.com

\begin{abstract}
Analyses of precipitation (1961-2010) from 39 meteorological stations in the Tarim River Basin revealed a trend from dryer towards wetter conditions induced by an increase of the number of wet extremes. A first (19611986) and second (1987-2010) period are the basis for a dynamical analysis of changing drought and wetness extremes which are closely related to cyclonic activity over the European continent and circulation anomalies in the Northern Hemisphere mid-latitudes. Wave train, cyclone tracks, water flux and potential vorticity (PV) front analysis of the wet and dry months show the following result: (1) The extreme wet and dry cases in winter and summer are characterized by distinguished wave train patterns upstream of the Tarim River Basin. All wave trains originate in the Atlantic-European sector pointing towards wave train dynamics as one possible mechanism underlying the connection patterns observed. (2) The selected extreme cases show that exceptional precipitation events can be connected to characteristic cyclone tracks and a PV front in the upper troposphere even if cyclone tracks never cross the Tarim Basin. Extremely wet winters are characterized by cyclone tracks close to the western and northern boundary
\end{abstract}

Hartmut Borth

hartmut.borth@uni-hamburg.de

1 State Key Laboratory of Lake Science and Environment, Nanjing Institute of Geography and Limnology, Chinese Academy of Sciences, Nanjing 210008, China

2 Center for Earth System Research and Sustainability, CliSAP, University of Hamburg, 20144 Hamburg, Germany

3 Max Planck Institute for Meteorology, 20144 Hamburg, Germany

4 Leibniz-Institute of Atmospheric Physics, 18225 Kühlungsborn, Germany of the Tarim Basin whereas, during extremely dry winters, such cyclone tracks are absent. Wet summers are characterized by long-lived cyclonic anomalies at the north western corner of the Tarim River Basin [see also (3)]. During dry summers such anomalies are absent. (3) On a more local level the hydrological extreme events are linked to special dynamical structures of the upper tropospheric PV front. In winter strong (extreme) precipitation is connected to a strong non-linear wave development or a wave-breaking event over the Tarim River Basin. Together with non-linear wave development moisture and precipitation areas are advected towards the Tarim River Basin. In dry winters the upper tropospheric PV front is much more zonally oriented and wave-breaking is less frequent. Strong precipitation events are connected to strong breaking events and to the formation of long-lived nearly stationary cyclones over or north of the Tarim River Basin during extremely wet summer months.

Keywords Standardized precipitation index $\cdot$ Aksu Tarim River Basin · Drought and wetness - Geopotential height . Mid-latitude dynamics $\cdot$ Cyclone tracks · Potential vorticity front

\section{Introduction}

The Tarim River Basin (roughly between $74^{\circ}-90^{\circ} \mathrm{E}$ and $35^{\circ}-43^{\circ} \mathrm{N}$ ) is one of the largest endorheic regions in China and one of the largest inland river basin (covering about 1 million square kilometers). It includes the Taklamakan desert and the Tarim river and its tributaries.

The atmospheric dynamics controlling the Tarim River Basin precipitation has been analyzed showing that largescale circulation indices and hydrological extremes are 
correlated negatively with polar vortex related indices, and positively with subtropical high related indices. Also other large-scale circulation indices considered suggest a close relation between extremes of the hydrological cycle in the Tarim River Basin and large-scale mid-latitude circulation in particular in the Atlantic and European sector (Wang et al. 2014). Time series from paleo and more recent climate archives show oscillations between dry and wet periods since at least 4000 years (Zhao et al. 2012; Chen et al. 2006a) and a connection to climate extremes in the NorthAtlantic sector (Bond et al. 1997). On an interannual time scale teleconnection patterns are found linking extremes of the hydrological cycle on different continents (Lau and Weng 2002; Wallace and Gutzler 1981; Ding and Wang 2005; Conversi et al. 2010; Zhu et al. 2011). Regular fluctuations between dry and wet states and its dependence on climate can also be observed and simulated on a more local scale (Chen et al. 2006b, 2008).

As precipitation in the plain region is usually less than $50 \mathrm{~mm} /$ year, the runoff generated in mountainous area evaporates in the low plains. The precipitation is mainly affected by three atmospheric circulation systems: the Indian and South-East Asian Monsoon and the mid-latitude circulation, which interact with each other leading to considerable variability and making the hydrological feedbacks quite different from those in other regions. In the context of global climate change, it has intrigued great interest in estimating possible changes in natural water resources in regions like the Tarim basin (Tao et al. 2011), especially in evaluating the possible consequences associated with extreme hydrological events, which pose serious risks to human life and entail substantial socio-economic and environmental damages. In part I of this paper hydrological droughts and wetness in the Tarim River Basin (Tao et al. 2015) are analyzed based on precipitation data between 1961 and 2010 from 39 meteorological stations in the Tarim River Basin. A principal component analysis (PCA) has been employed to study the main spatial patterns and the temporal variability of the SPI. A trend analysis shows that the hydrological cycle changes from dryer towards wetter conditions by an increase of the number of wet extremes. Subdividing the period of analysis into a first (1961-1986) and a second (1987-2010) period this change can be clearly seen in a shift of the probability distribution functions of precipitation events. Using geopotential height fields on $500 \mathrm{hPa}$ and atmospheric large-scale ciruclation indices a close connection to mid-latitude circulation variability is found which is in agreement with previous works (Diffenbaugh et al. 2013; Zhang et al. 2013; Kingston et al. 2007; Talaee et al. 2014).

However, most of the previous studies focus only on statistical aspects of the relationship between hydrological extremes and large-scale atmospheric circulation. To further investigate the mechanisms connecting hydrological extremes in the Tarim River Basin and mid-latitude atmospheric dynamics the present paper analyzes the atmosphere as follows: (a) composites of mid-tropospheric geopotential height fields for specific months and the corresponding seasonal quasi-stationary wave patterns, (b) cyclone tracks and (c) upper tropospheric PV fields (Ertel 1942). By combining three different points of view we wish to gain a more complete picture of the possible mechanisms which lead to the fluctuations of the hydrological cycle.

Section 2 gives a brief overview on the data sources and main analysis methods. In Sect. 3 the large-scale atmospheric circulation setting is introduced describing stationary and quasi-stationary waves and geopotential height fields. The connection between hydrological extremes and large-scale mid-latitude dynamics using cyclone tracks, upper tropospheric PV fields and precipitation fields is presented in Sect. 4. In Sect. 5 results are discussed and summarized.

\section{Data and methods}

Wave activity fluxes (WAF) are calculated according to Plumb (1985) and according to Takaya and Nakamura (1997). WAF based on Plumb (1985) indicates the seasonal climatological stationary wave pattern, while WAF based on Takaya and Nakamura (1997) reveals the seasonal and longitudinal deviation from climatology. The presented analysis focus on $300 \mathrm{hPa}$. Composites of geopotential height fields on $500 \mathrm{hPa}$ corresponding to extreme events are formed following Fraedrich (1994) and Hellström (2005). The cyclone tracks are determined from anomalies of the $1000 \mathrm{hPa}$ geopotential height fields (Blender et al. 1997). The PV dynamics are analyzed on the $320 \mathrm{~K}$ (winter) and $330 \mathrm{~K}$ (summer) isentrope (Hoskins et al. 1985). Geopotential height fields $(500 \mathrm{hPa})$, quasi-stationary waves, cyclone tracks and PV fields are all deduced from ECMWF re-analysis ERA-40 (Uppala et al. 2006) retrieved from the World Data Center for Climate (WDCC) in Germany. The data set is analyzed on a $2.5^{\circ} \times 2.5^{\circ}$ horizontal resolution. The 39 meteorological stations in the Tarim River Basin and the data set of daily precipitation are described in detail in part I of this paper (Tao et al. 2015).

To find the extreme wet and dry months in the Tarim River Basin we follow (Tao et al. 2015). After averaging the daily precipitation of the 39 stations, the SPI is used to determine extreme wet and dry months in summer (JJA) and winter (DJF) during the years 1961-2002. The results are summarized in Table 1 . The most extreme wet/dry month in winter is January 1994/December 1967. In summer the most extreme wet/dry month is June 1987/ 
Table 1 Extreme and severe wet and dry months in summer (JJA) and winter (DJF) of the Tarim River Basin from 1961 to 2002 classified by 1 month SPI

Fig. 1 Climatological wave activity flux (horizontal WAF, arrows in $\mathrm{m}^{2} / \mathrm{s}^{2}$ ) according to Plumb (1985) for stationary waves in $\mathbf{a}$ winter and $\mathbf{b}$ summer on $300 \mathrm{hPa}$. Shaded regions indicate the geopotential perturbation (defined as deviation from zonal mean)

\begin{tabular}{|c|c|c|c|c|c|c|c|}
\hline \multicolumn{2}{|l|}{ Wet summer } & \multicolumn{2}{|l|}{ Wet winter } & \multicolumn{2}{|l|}{ Dry summer } & \multicolumn{2}{|l|}{ Dry winter } \\
\hline Year/month & SPI & Year/month & SPI & Year/month & SPI & Year/month & SPI \\
\hline 1981/08 & 2.3 & $1976 / 12$ & 2.35 & 1971/06 & -2.27 & 1963/01 & -1.85 \\
\hline 1987/06 & 2.37 & 1994/01 & 2.72 & 1984/08 & -2.99 & $1967 / 12$ & -1.89 \\
\hline 1996/07 & 2.21 & 2002/01 & 2.52 & 1985/07 & -2.29 & $1983 / 02$ & -1.84 \\
\hline
\end{tabular}
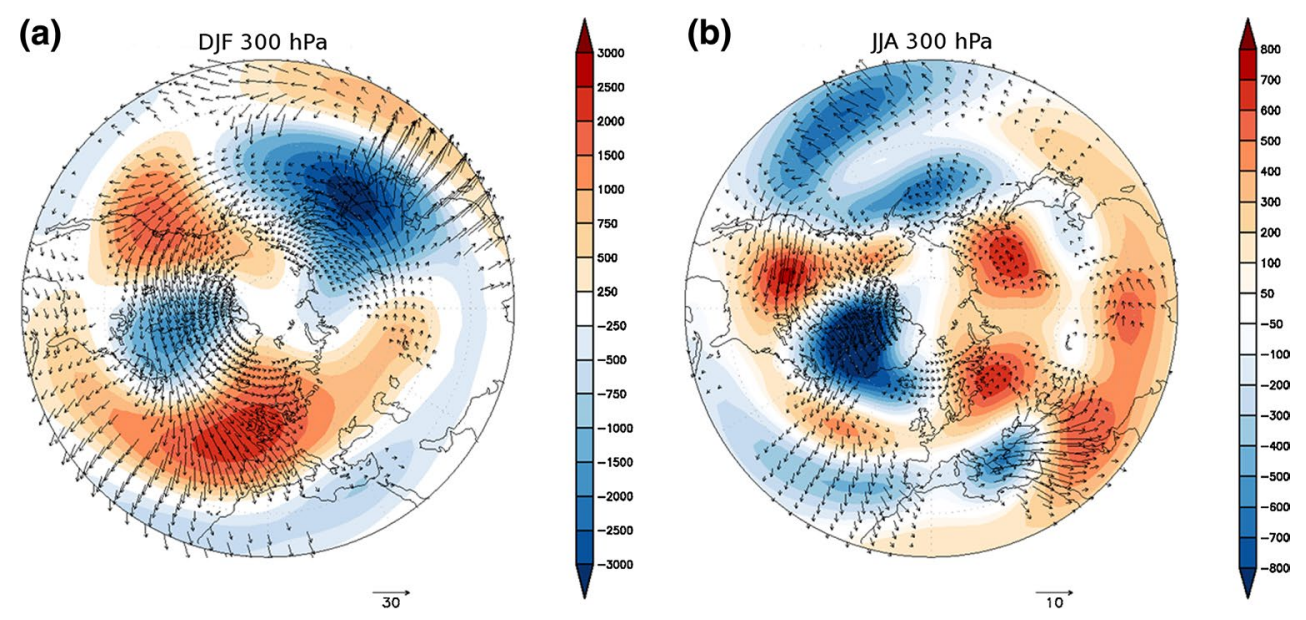

Fig. 2 Quasi-stationary wave activity flux according to Takaya and Nakamura (1997) for two winter seasons a DJF 1967/1968 (dry) and b DJF 1993/1994 (wet). Shaded regions indicate the streamfunction perturbation (defined as deviation from climatology), here multiplied by $10^{6}$. The arrows indicate the horizontal components of the Flux in $\mathrm{m}^{2} / \mathrm{s}^{2}$

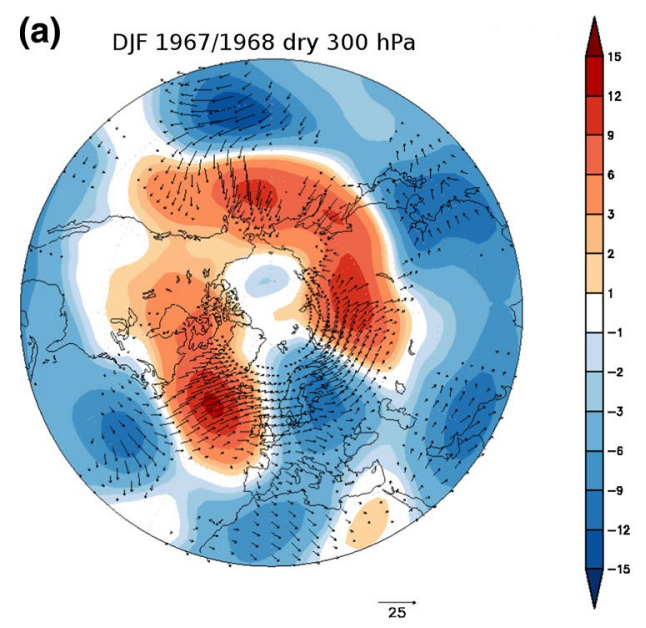

August 1984. Having in mind that in the Tarim River Basin extremes are rare events, our analysis is restricted to the three most extreme wet/dry months during summer and winter seasons.

\section{Waves and composites of geopotential height}

Using the selection of months given in Table 1, we describe to what extent wet and dry extremes can be connected to the large-scale circulation by analysing waves and composite means of the $500 \mathrm{hPa}$ geopotential height field.

\subsection{Stationary and quasi-stationary waves}

The following stationary and quasi-stationary waves fields show how the most extreme wet and dry months of Table 1 are embedded into seasonal wave patterns. The climatological mean shows one pronounced wave train starting at the Gulf of Alaska, North America, Greenland and then splits into a northern and a southern branch during winter (Fig. 1a). Another wave train emanates over Siberia and splits into two parts. The most extreme dry case (embedded into the season DJF 1967/1968) is characterized by an anomalous amplified wave train towards a Siberian anticyclonic perturbation (Fig. 2a). This anticyclonic perturbation 

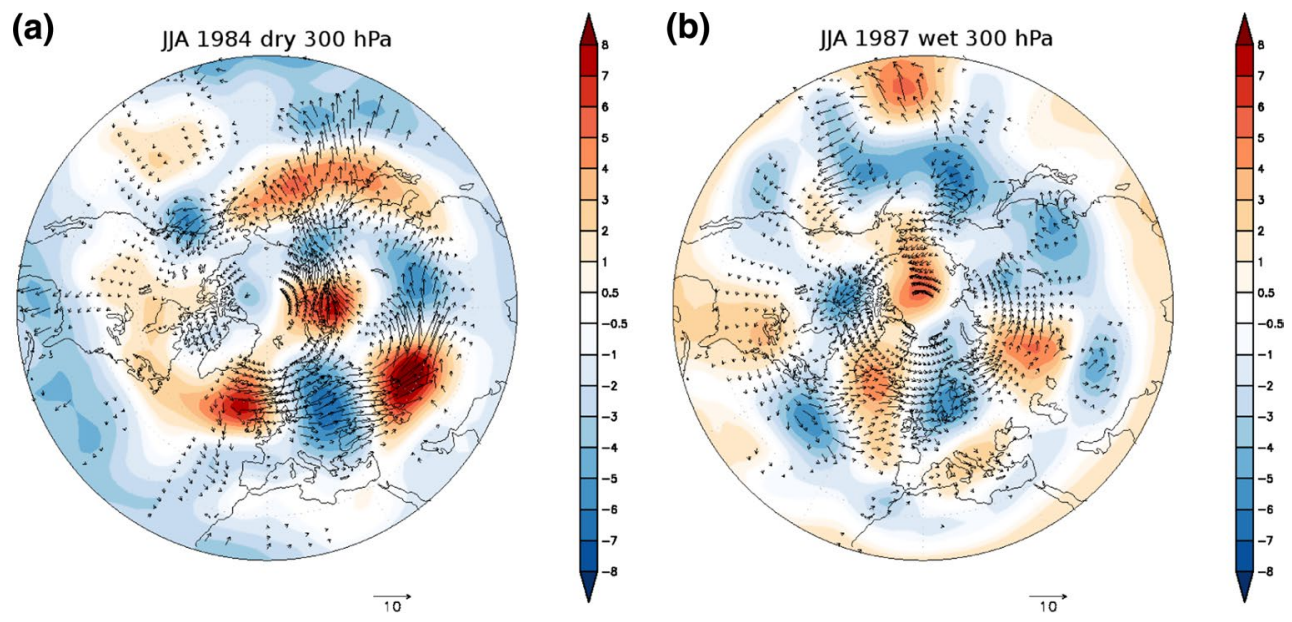

Fig. 3 Same as Fig. 2 but for the most extreme a dry and $\mathbf{b}$ wet summer month

implies that the Tarim basin comes under the influence of this high pressure system which supports in winter dry conditions. The situation changes, if quasi-stationary waves are considered for the most extreme wet case during winter 1993/1994 (Fig. 2b). Cyclonic perturbations are favored to the north of the Tarim basin, which indicates their influence in this region.

In climatological perspective, the Asian continent is characterized by anticyclonic perturbations in summer (Fig. 1b). The wave train emerging from the Mediterranean splits into a northern and a southern branch. The northern branch unifies west of the Ural Mountains with a northern wave train starting to the east of Greenland. If the most extreme dry case is considered (JJA 1984), the wave train starting to the east of Greenland is amplified and splits into a northern and a southern branch east of the Caspian Sea (Fig. 3a), supporting an anticyclonic system just to the west of the Tarim basin and favors dry conditions.

The northward wave train starting at Greenland is amplified and shifted to the north for the most extreme wet case in summer 1987 (Fig. 3b). As a result, the anticyclonic perturbation is displaced more to the north and cyclonic perturbations are favored over or to the near of the Tarim basin. This shift of the anticyclonic-cyclonic-anticyclonic pattern highlights the difference between the most extreme wet and dry cases.

\subsection{Geopotential height}

To correlate wet and dry extremes (Wei et al. 2003) with characteristic large-scale atmospheric circulation systems we form composite means of the geopotential height fields on $500 \mathrm{hPa}$ using the three wettest and driest months in winter and summer shown in Table 1. Extreme dry winters (Fig. 4a) are characterized by a strong ridge centered over the Tarim River Basin. In a similar way during extreme dry summers (Fig. 4b) the Tarim River Basin is located near a ridge. Extreme wet winters on the other hand (Fig. 4c) are characterized by a much more zonal flow whereas during extreme wet summers (Fig. 4d) the Tarim River Basin is located near a trough (see also Zhao et al. 2006). In general, air masses are advected from westerly directions in some cases more from the south or north. Subtracting the dry composite means from the wet composite means the following signals in the geopotential height fields appear: In winter (Fig. 5a) the anomaly pattern in the geopotential height field occurs with a cyclonic anomaly $(-)$ located over Siberia and an anticyclonic anomaly $(+)$ located over south-east China. A more detailed analysis of the dynamics of the upper tropospheric PV front and the connected cyclone tracks and precipitation events show that the upstream circulation determines the hydrological fluctuations and extremes during winter (see below).

In summer (Fig. 5b), we encounter a different pattern. Wet extremes are characterized by a large crescent-like ridge over Asia extending from the Pacific Ocean to the Black Sea and a relative dipole anomaly with an anticyclone centred over the Ural Mountains and a cyclone centred over Tajikistan. The dynamics of the upper tropospheric PV front (see below) shows that this enhanced transport of air masses can be connected to cut-off cyclones to the north or over the Tarim Basin. These cut-off cyclones are connected to strong precipitation events and can be connected to long-lived cyclonic anomalies at the surface (see cyclone tracks below). The column integrated moisture (not shown) is advected predominantly from westerly, northwesterly and south-westerly directions during both extreme wet and moist months. Precipitation is only observed for special cyclone tracks and non-linear upper tropospheric PV-front dynamics (see below). During wet summers the 
Fig. 4 Composites of geopotential height fields (in $100 \mathrm{gpm})$ on $500 \mathrm{hPa}$ (black box indicates location of Tarim River Basin): of the three extreme a dry winters (center of ridge), $\mathbf{b}$ dry summers (near center of ridge), $\mathbf{c}$ wet winters (zonal flow) and $\mathbf{d}$ wet summers (near center of trough)
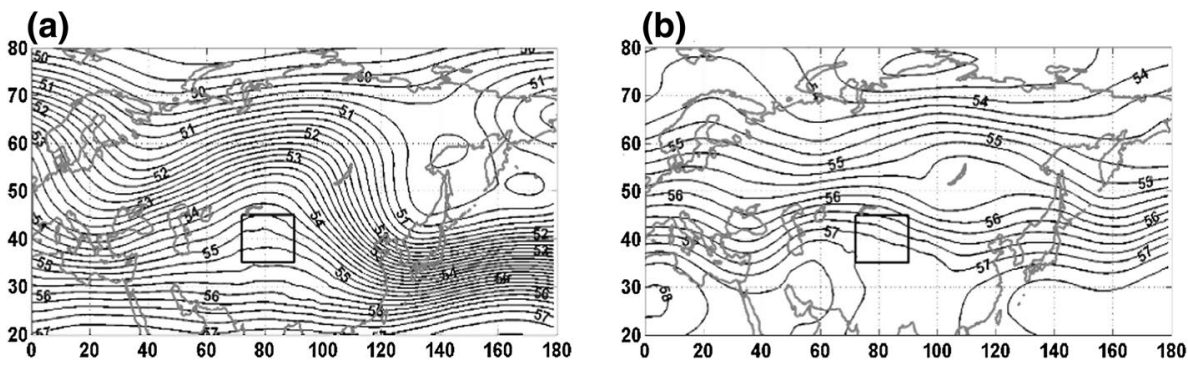

(c)

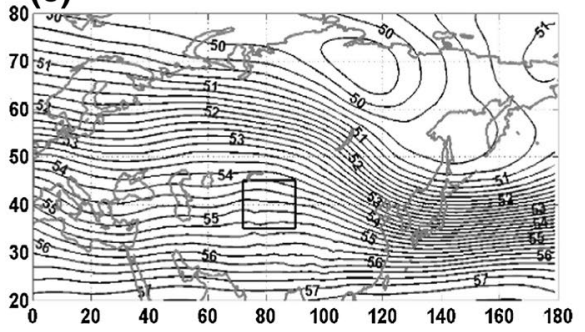

(d)

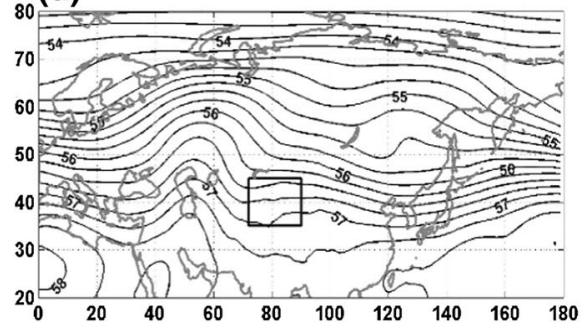

(a)

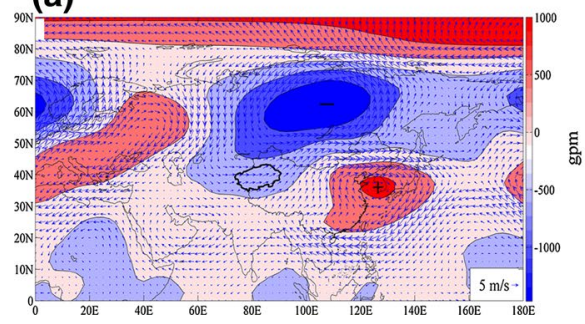

Fig. 5 Difference of geopotential height fields (blue and red shading) and wind fields (arrows) between the composites of the three extreme wet and dry months $\mathbf{a}$ in winter and $\mathbf{b}$ in summer. The most promi-

whole sector of the northern hemisphere considered is moist.

\section{Cyclones and potential vorticity}

To obtain a more complete view for the dynamical processes responsible for the connection of large-scale midlatitude circulation and hydrological extremes, composites of the cyclone tracks are considered for the three wettest and driest months during winter and summer. The months used are the same as those for the composites of the geopotential height (Table 1).

\subsection{Cyclone tracks}

The cyclone tracks (Fig. 6) are deduced from the anomalies of the $1000 \mathrm{hPa}$ geopotential height fields using the algorithm by Blender et al. (1997). In Fig. 6 the location of the observation stations are marked by black triangles. Areas which are above $1500 \mathrm{~m}$ are shaded grey. A cyclone track is

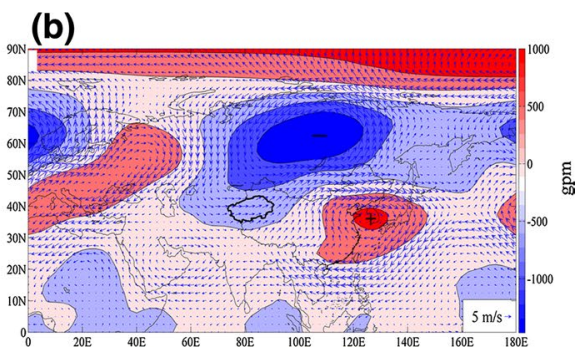

nent positive and negative patterns of the geopotential height field differences are denoted by plus and minus signs

indicated by a continuous line (in cyan), its starting point is indicated by a blue dot and the end point by a red dot. For nearly stationary cyclones the size of the red dots indicates the live time of a cyclone, which is in particular important for the summer season. Cyclone positions are plotted every $6 \mathrm{~h}$ (black dot). Due to the altitude of the Tarim river Basin, cyclone tracks cannot be detected over this region, especially if the geopotential at $1000 \mathrm{hPa}$ is considered, but the analysis of the upper tropospheric PV front, precipitation patterns and station data shows that cyclones can be connected to precipitation events in the Tarim River Basin if their tracks do not pass too far beyond the western and/or northern borders of the Tarim River Basin.

In dry winter seasons, the hydrological cycle solely depends on mid-latitude dynamics. The seasonal quasi-stationary wave pattern and the geopotential height anomalies show that drought and wetness are connected to different geographical locations of the embedded cyclone tracks. Especially, dry winters are characterized by a cyclone track free region to the north and north-west of the Tarim Basin (Fig. 6a). The comparison with the geopotential height 
Fig. 6 Composites of cyclone tracks of the three extreme $\mathbf{a}$ dry and $\mathbf{b}$ winter months. Longitudes and latitudes are given in degrees west and north. Cyclone positions (cyan solid line) are given every $6 \mathrm{~h}$ (black dots). Start/end of trajectory is denoted by a blue/red disk (for more details see text)

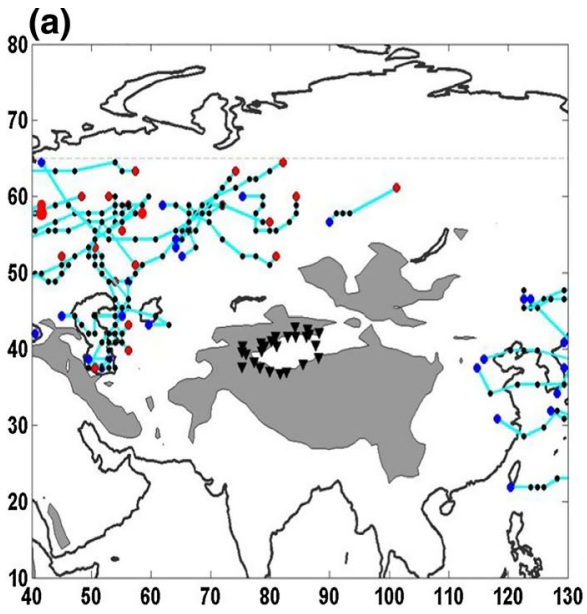

anomaly (Fig. 5a) and the quasi-stationary wave pattern (Fig. 2a) indicates that the transient eddies could maintain the high pressure anomaly just to the north of the Tarim Basin which bring cold and dry air into the region.

During wet winters the distance between detected cyclone tracks and the region to the north and north-west of the Tarim Basin (Fig. 6b) decreases. The cyclone tracks passing close (still beyond the mountain ranges enclosing the Tarim Basin) to the western and northern boundary to the Tarim Basin lead to strong precipitation events in the winter dry season (see also next section).

In wet summers the hydrological cycle is influenced by mid-latitude and monsoonal dynamics. Extremely wet months are distinguished by long-lived nearly stationary cyclones close to the western and north-western boundary of the Tarim Basin. These long-lived cyclonic surface anomalies are connected to strong cut-off cyclones of the upper tropospheric PV front (see below), which themselves are connected to strong precipitation events. During extremely dry months these long-lived cyclones are not present. At the same time much more cyclone tracks are located over the Caspian Sea, indicating that the cyclonic activity is concentrated far west of the Tarim River Basin. A more detailed picture can be deduced from the joint analysis of cyclone tracks, precipitation and the connected dynamical structures of the upper tropospheric PV front.

\subsection{Upper tropospheric potential vorticity front and precipitation}

Here, the evolution of the upper tropospheric isentropic PV front is considered. The isentropic PV is calculated from atmospheric fields of the ERA-40 data set. For the winter seasons, the $320 \mathrm{~K}$ isentrope and for the summer the $330 \mathrm{~K}$ isentrope are considered. For the extreme wet and dry months the synopsis of dynamical patterns of the upper tropospheric potential vorticity front, 6 hourly precipitation fields, station data and connected cyclone tracks show that the rainy zones located south and west of a cyclone (and dynamically linked to the cyclone) sweep the Tarim Basin and are responsible for precipitation events. These events are weaker during winter dry season and stronger during summer wet season (see also climatology and probability distribution of precipitation in Tao et al. 2015). Figures 7 and 8 present the typical dynamical evolution of circulation systems which lead to strong precipitation events over the Tarim River Basin in the dry winter season.

The first example (Fig. 7) taken from the wettest winter month (January 1994), shows the evolution of a cyclone with a track allowing the precipitation zones connected to the cyclone to reach the Tarim Basin (The cyclone track relevant for the Tarim Basin, is the track close to the bounding box. The other active cyclone tracks further north are not relevant and are connected to other precipitation areas). At the same time the precipitation zone south of the cyclone track is connected to the eastern crest of the non-linearly evolving wave of the upper tropospheric PV front. The column integrated moisture field (not shown) indicates that along with the precipitation also moisture is advected to the Tarim Basin. This picture is consistent with the preferred mid-tropospheric air mass transport from the north-west to the south-east upstream of the Tarim River Basin (Fig. 4) deduced from the composite means. During January 1994 several similar circulation systems are responsible for precipitation events in the Tarim Basin. The rhythm of precipitation events in the Tarim Basin deduced from the ERA-40 data set correlates very well with the daily precipitation measured at the meteorological stations considered (for more information on the meteorological stations see Tao et al. 2015). For a more detailed evaluation of the hydrological cycle in the ERA-40 data set see also Hagemann et al. (2005).

The second example (extremely wet: December 1976, see Table 1) presents a similar picture. The precipitation and the column integrated moisture is transported (not 
Fig. 7 Potential vorticity on $320 \mathrm{~K}$ isentrope with active cyclone track and $6 \mathrm{~h}$ precipitation (black box: Tarim River Basin). Four snapshots (a-d) (12 $\mathrm{h}$ apart), starting the 4 January 1994 6:00 UTC: Shown are isolines for 2.5, 3 and $3.5 \mathrm{PV}$ units, the lower threshold is 2.5 PV units, areas with PV values larger than 3.5 PV units are light gray. The $6 \mathrm{~h}$ precipitation is visualized by 2,4 and $10 \mathrm{~mm} /$ day isolines and the colors cyan/ blue and magenta, the lower threshold is $0.9 \mathrm{~mm} / \mathrm{day}$. Tracks of active cyclones are given by a red dotted line for $6 \mathrm{~h}$ time interval; large disk denotes position at snapshot time

Fig. 8 Same as in Fig. 7 with four consecutive snapshots in December 1976, a day 11, 12:00 UT, b day 12, 12:00 UTC, $\mathbf{c} 12 \mathrm{~h}$ later and $\mathbf{d}$ again $12 \mathrm{~h}$ later

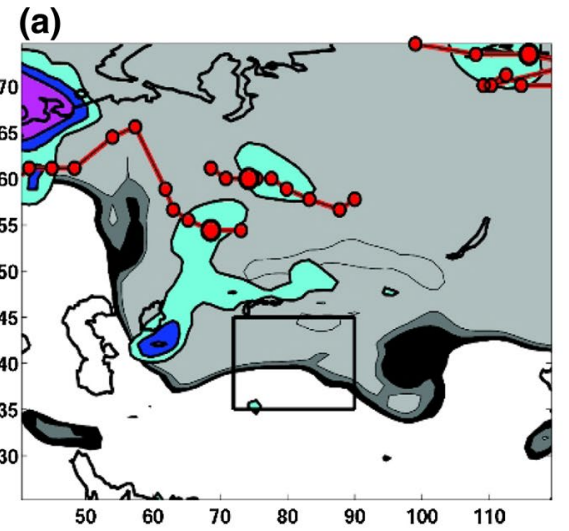

(b)

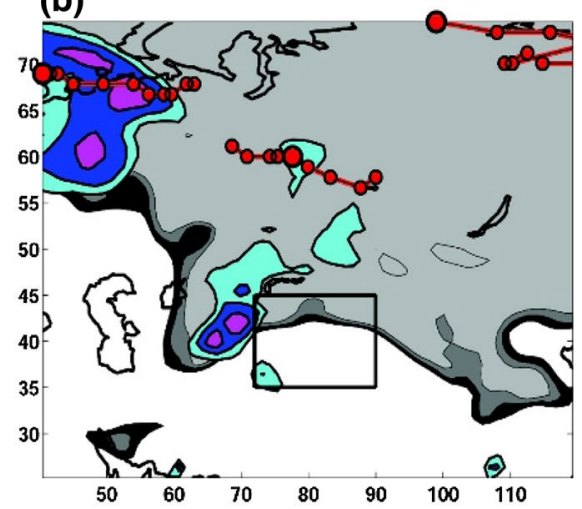

(c)

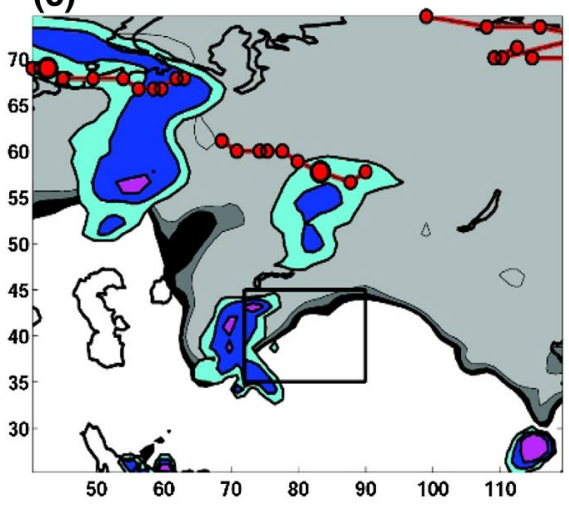

(d)

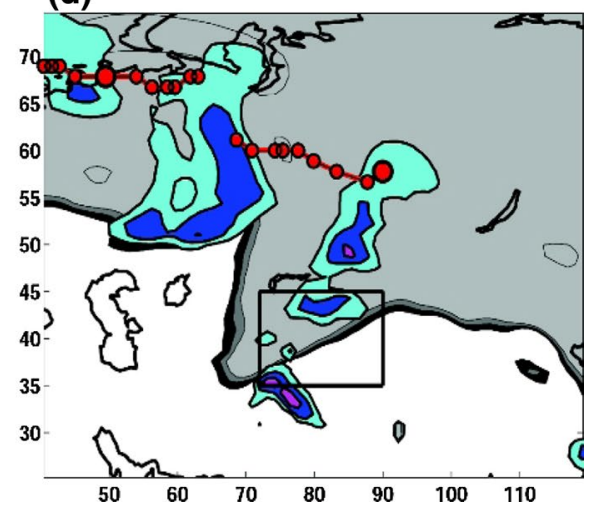

(b)

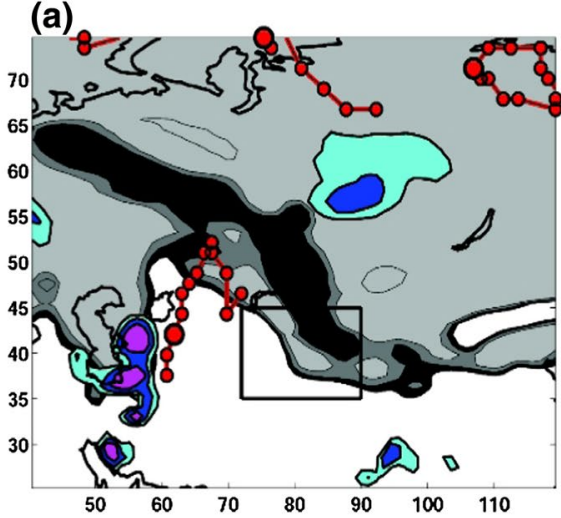

(c)

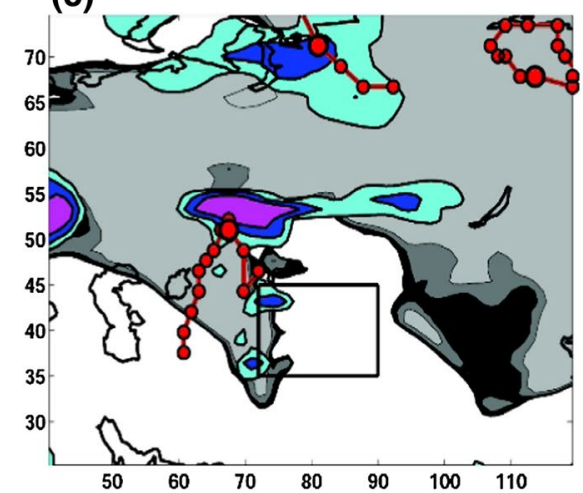

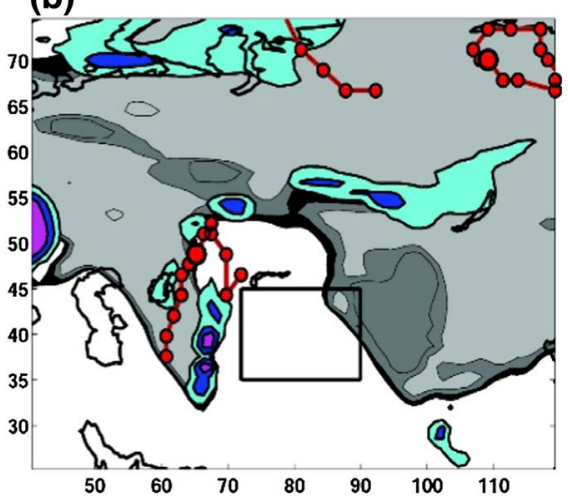

(d)

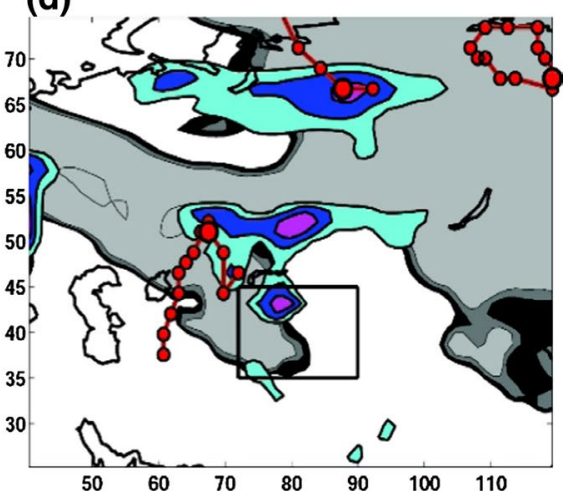


Fig. 9 Composite of cyclone tracks of the three extreme a dry and $\mathbf{b}$ wet summer months (annotation as in Fig. 6)

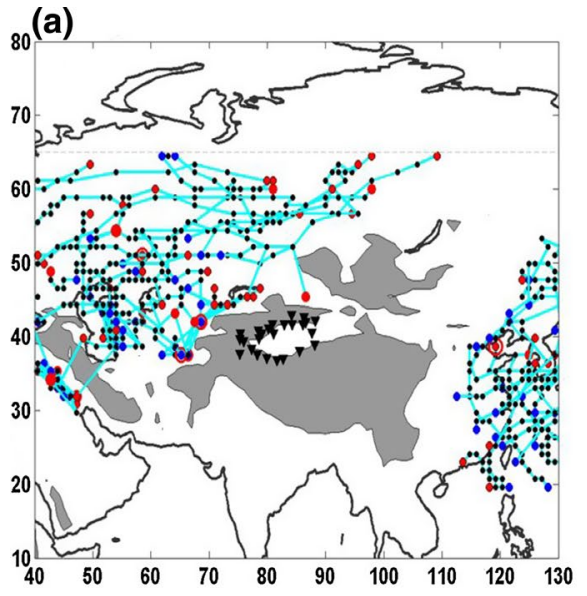

shown) from the west. The cyclone follows a track starting from the south and moving northwards and back to the south quite close to the north-western corner of the bounding box of the Tarim Basin (see also composite of cyclone tracks in Fig. 6b). The upper tropospheric PV front evolves non-linearly, moves from west to east and breaks over the Tarim Basin. During breaking events the evolution of cyclone and PV front activity is more confined spatially so that the Tarim Basin is influenced for a longer period. This gives the possibility for longer precipitation events. During extremely dry winter months, on the other hand, less cyclone tracks close to the Tarim Basin and less or no strong breaking events of the upper tropospheric PV front over the Tarim Basin are observed. However, there are meteorological situations where weak non-linear wave evolution or breaking events are not connected to precipitation upstream of the Tarim Basin. This indicates that not sufficient moisture is deposited in the relevant upstream regions. The column integrated moisture indicates that also during extremely dry winters moisture is advected over the Tarim Basin, but rain is induced only further to the north-east closer to the cyclone tracks where convergence is induced. In summary, for the extreme cases we analyze the dynamical patterns described above are necessary to induce precipitation events over the Tarim Basin. There are occasions where the air mass transport by the atmospheric circulation systems is not sufficient to induce precipitation events, since the air masses are too dry. The westward shift of cyclone tracks during wet winters and the characteristic direction of the tracks going from southwest to north-east (Fig. 6b) indicate that cyclone evolution and the characteristics of the connected breaking events are important for the hydrological extremes in the Tarim Basin. The composite means (Fig. 4) show that the geopotential height upstream over southeast Europe go in parallel with differences in upper tropospheric PV front Rossby wave breaking. Due to the specific length and time scales of the PV front dynamics, breaking events over Europe and
Central Asia are connected. This "dynamic teleconnection" may help to understand processes which are at the base of the statistical teleconnections between Europe and Central Asia deduced from precipitation data and climate archives. To understand to what extent this connection can be established also in other cases a more extensive investigation of the whole period is necessary. For more details on trends and teleconnections of hydrological extremes in Europe based on a SPI analysis see e.g., Bordi and Sutera (2001) and Bordi et al. (2006).

During wet summers, the connection between mid-latitude dynamics and hydrological extremes is more intricate since the Monsoon plays an important role. The first observation is that the cyclone density is much higher during summer (Fig. 9) than during winter (Fig. 6). Moreover, cyclone positions and tracks typical for wet winters are present both during wet summers and during dry summers (Fig. 9). During dry summers cyclones with a lifetime of several days (larger red dots in Fig. 9a) are connected to precipitation events of intermediate strength. Wet summers are characterized by the presence of nearly stationary cyclones with lifetimes between 5 and 10 days (large red dots in Fig. 9b).

The column integrated moisture over the Tarim River Basin (not shown) is much higher in summer than in winter also during dry periods. Figures 10 and 11 show the evolution of the circulation systems connected to extreme precipitation events for two of the extremely wet summer months. The PV front is typically 10 degrees further to the north than in winter. But the Tarim Basin is still strongly influenced by non-linear wave breaking events and especially by nearly stationary cut-off cyclones which induce recurring precipitation events over the Tarim Basin. Figure 10 shows a strong precipitation event during the wettest month (Table 1) connected to a breaking event which leads to a PV cut-off cyclone which finally leads to a cyclonic surface signal (cyclone track). Again, the active cyclone tracks further to the north are irrelevant to the dynamics. Figure 11 gives another example. In this case the cut-off 
Fig. 10 PV on the $330 \mathrm{~K}$ isentrope. Four snapshots starting the 21 June 1987 00:00 UTC (12 $\mathrm{h}$ apart) (a-d) (annotation as in Fig. 7)

Fig. 11 Same as in Fig. 10, for four snapshots starting the 14 July 1996 at 00:00 UTC (12 h apart) (a-d) (annotation as in Fig. 7) (a)

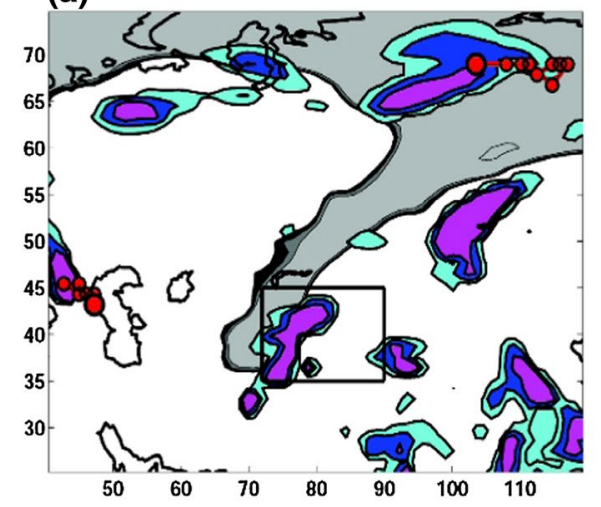

(c)

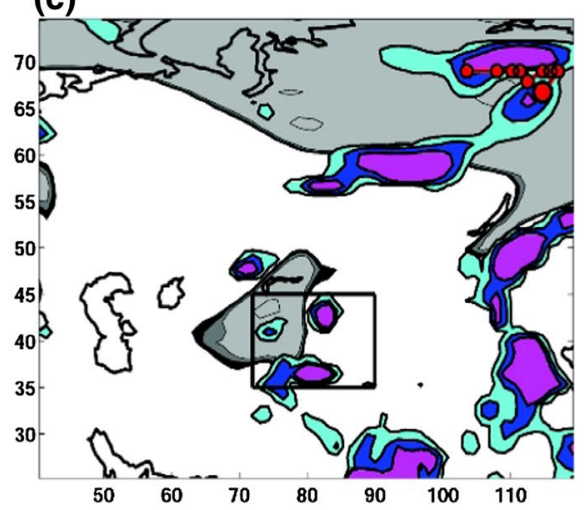

(a)

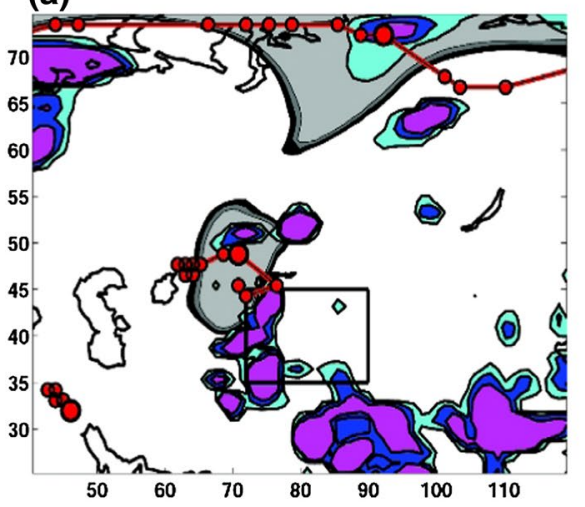

(c)

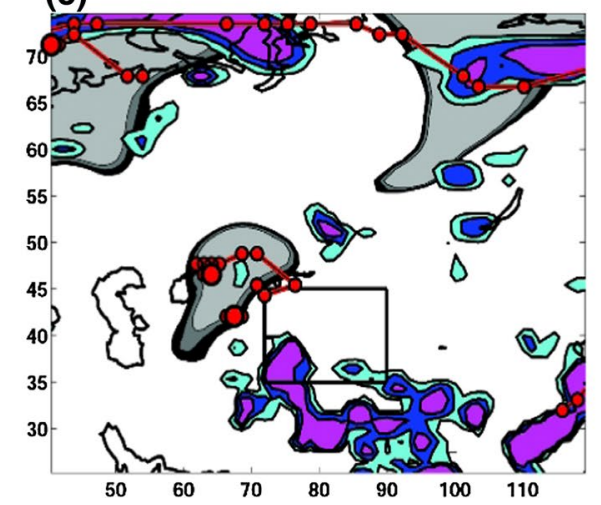

(b)

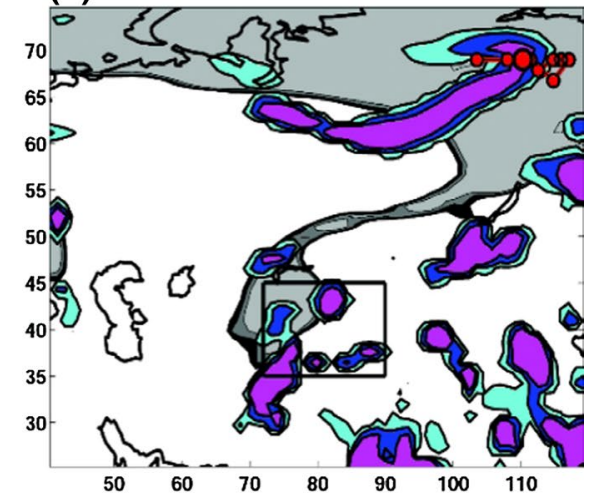

(d)

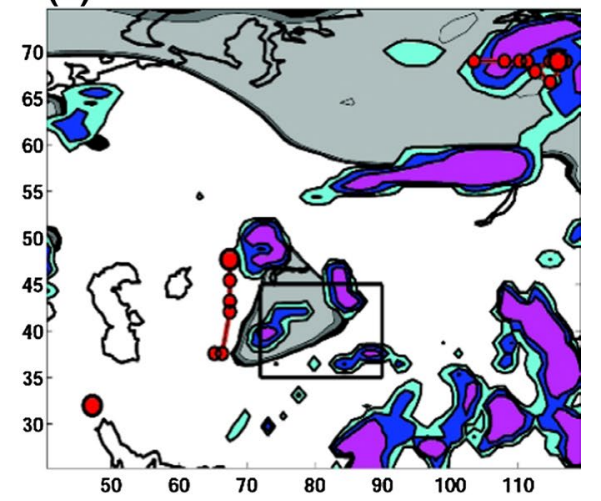

(b)

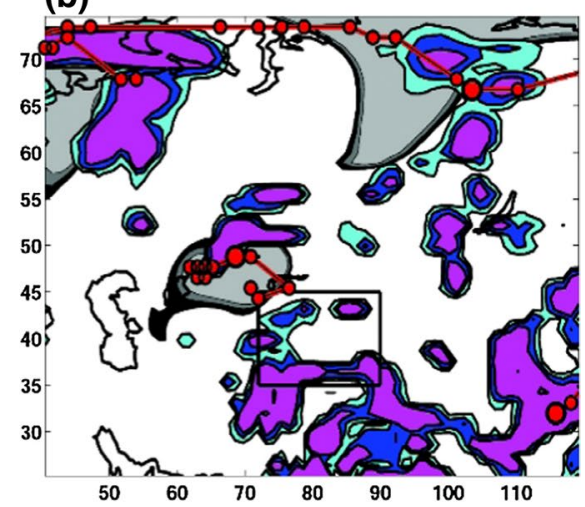

(d)

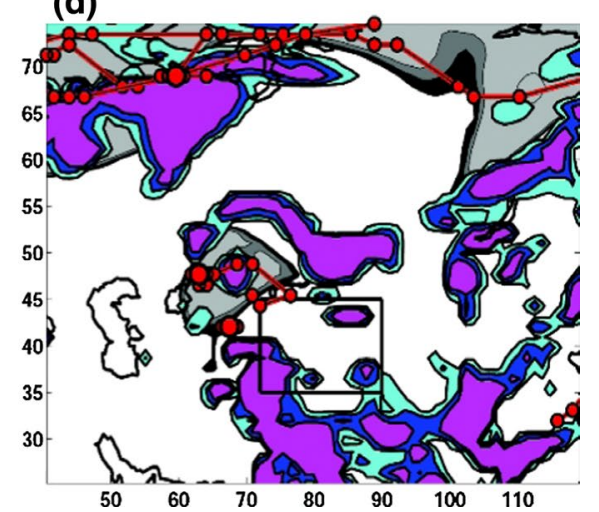


cyclone survives for several days inducing recurring precipitation events over the Tarim Basin. During extremely dry summer months the PV front is much more zonally oriented and no wave breaking events are observed over the Tarim Basin. Moreover, a recurring formation of localized cyclonic anomalies of the upper tropospheric PV fields are observed at the southern boundary of the Tarim Basin. The extreme cases studied indicate that mid-latitude dynamics plays an important role for the hydrological cycle of the Tarim Basin also during summer. The time evolution of the column integrated moisture reveals that mid-latitude circulation systems often advect moisture across the western and northern boundary. Moisture advection across these boundaries can be observed both during extremely wet and dry summers. Wet summers are distinguished by the characteristics of the mid-latitude dynamics. Comparing in our cases atmospheric dynamics with precipitation observations the rhythm (occurrence, duration and frequency) of precipitation events is determined by the PV dynamics connected to cyclones (breaking, cutoff and specific dynamics of cutoff cyclones).

\section{Discussion and conclusion}

The large-scale mid-latitude circulation systems connected to hydrological extremes in winter and summer are analyzed to find the atmospheric patterns and physical mechanisms underlying the extremes of the hydrological cycle in the Tarim River Basin as well as the statistical correlations and teleconnections between the North-Atlantic-European sector and Central Asia. The geopotential height field on $500 \mathrm{hPa}$ can clearly distinguish between extremely wet and dry winter and summer months. In all cases the air masses are advected predominantly from the west.

Wet and dry extremes are distinguished by different geographical locations and different amplitudes of meridional excursions of the isolines of the geopotential height field. The mean of the wet winter extremes are characterized by a strongly zonal flow in contrast to a divergent meandering flow with a maximum over the Tarim River Basin during dry winters, with a splitted flow into a northern and southern part (anticyclone). The mean of the wettest months during summer is characterized by a strong northward meander of the flow at the western boundary of the Tarim River Basin. Air masses are advected across the western and northern boundary along with a flow convergence over the Tarim River Basin. A generalization to a climatology of the hydrological variability during summer is left to future studies. The advection of the column integrated moisture is consistent with the picture given by the mean air mass transport deduced from the composites of monthly averaged geopotential height fields. The analysis of wave trains shows that the above more local differences of the mid-latitude circulation can be connected to different wave train dynamics upstream of the Tarim River Basin with an origin in the Atlantic and European sector. The geopotential height anomalies seem to enhance the link with the monsoonal circulation southeast of Tarim. A more thorough analysis of the teleconnection patterns and comparison with results of Bothe et al. (2010) on the neighboring Tibetan Plateau is left for future research. During winter, increased wetness occur over southeast China starting from the 1990s (Zhang et al. 2014a, b). At least in the considered cases, the mid-latitude circulation systems influence the extremes of the hydrological cycle during winter and summer. Our analysis might help to get a better understanding on the ratio between the amounts of advected and locally recycled precipitation ( $\mathrm{He}$ and $\mathrm{Lu} 2013$ ) as well as a more general understanding for the water transport mechanisms in the Tarim River Basin (Wu et al. 2012). Simulations (Mannig et al. 2013) with a focus more on processes with a judicious choice of idealizations (e.g. northern boundary of monsoon area, position of PV front and ITCZ) can help to generalize connections found so far for extreme months to a wider class of climatological settings.

By analysing in a combined way mid-latitude cyclone tracks, the upper tropospheric potential vorticity front and hydrological extremes we have opened a new way to a more direct understanding of the dynamical causes leading to the European-Asian teleconnections found today and in the past (Zhao et al. 2012). The dynamics of the upper tropospheric potential vorticity front during the hydrological extreme events considered suggests that at least during winter specific breaking and cut-off events are responsible for hydrological extremes in the Tarim River Basin. Since perturbations travelling eastward along the PV front trigger breaking and cut-off events and since perturbations are themselves due to wave breaking and cut-off events upstream this view might provide direct explanation for the teleconnections. To give more weight to this picture in future analysis, more cases have to be investigated and a thorough analysis has to be carried out of the spatial and temporal scaling behavior of breaking and cut-off events in the European and Asian sector and possibly in the whole Northern Hemisphere. The characteristic differences of cyclone tracks underline this view. In winter we get a more clear picture as in summer, since the precipitation events are exclusively due to mid-latitude atmospheric circulation, while during summer the area is additionally influenced by the Monsoon. During summer, the most extreme precipitation events in the Tarim Basin are determined by the dynamics of the PV front and the connected cyclone activity. Since the moisture can be transported from the Monsoon areas located south and east of the Tarim River Basin it is not clear if the appropriate frontal dynamics is sufficient to trigger a precipitation event, it might well be that the Monsoon must be strong enough and in tune with the frontal dynamics. 
Since the rugged topography of the Tarim River Basin is under the influence of the Siberian anticyclonic circulation and the moderate influence of the southwest cyclonic circulation that brings moist air masses into the basin, future research has to demonstrate how much of the variability is due to cyclones, e.g. near the Caspian Sea and how much to the Monsoons. Thus future research requires mid-latitude dynamics to be linked with the monsoonal dynamics.

In summary we find the following connections between extreme wet and dry months and the large-scale atmospheric circulation:

1. Differences in wave-train dynamics link the AtlanticEuropean sector with the Asian sector where the Tarim River Basin is embedded. Extreme dry and wet months in summer are distinguished by a shift of a characteristic anticyclone-cyclone-anticyclone pattern in the wave activtity.

2. Extreme wet and dry months during winter and summer are characterized by a specific ridge and trough pattern in the $500 \mathrm{hPa}$ geopotential height fields.

3. Extreme wet/dry months during winter are characterized by the presence/absence of cyclone tracks not too far from the western and northern flanks of the Tarim River Basin. In summer extreme wet events are connected to long-lived cyclonic anomalies at the northwestern bounding box of the Tarim River Basin.

4. Extreme wet and dry months are most directly related to the upper tropospheric PV front. Wet/dry winters can be clearly distinguished by the presence/absence of non-linear PV-front wave-development or breaking events over the Tarim Basin. The time evolution of the PV-front shows that the precipitation fields are advected together with the column-integrated moisture across the western (south western or north western) boundary of the Tarim River Basin. Linking upper tropospheric PV-front dynamics with cyclonic signals at the surface shows clearly that cyclone tracks passing not too far from the western and northern boundary of the Tarim River Basin are connected to precipiation events there. Moisture is advected across the Tarim River Basin also during extremely dry months, what is missing is a characteristic PV-front evolution which can induce precipitation.

We find that the PV-front dynamics influences extremes of the hydrological cycle also in summer even if the mean position of the PV-front is located more than $1000 \mathrm{~km}$ to the north of the Tarim Basin. We can show that stong breaking events and long-lived cut-off cyclones off the northern boundary or over the Tarim River Basin are responsible for very strong precipitation events.
Acknowledgments This study was supported by the German Science Foundation DFG (cluster of excellence, Integrated Climate System Analysis and Prediction (EXC 177) and project, Climate change and water resources in western China (Aksu-Tarim), PAK 393) and the National Natural Science Foundation of China (No. 41101023). Hui Tao gratefully acknowledges receipt of a DAAD scholarship (German Academic Exchange Service). Support by the Max Planck Fellowship is appreciated (KF). A short visit (KF and Prof. Xiefei Zhi, 2012) sponsored by the (Urumqi) Institute of Desert Meteorology (IDM) of China Meteorological Agency (CMA) and discussions with the Director Dr. He Qing are greatfully appreciated as our discussions they were lying the foundation to this analysis. AS was supported by the German Science Foundation (DFG, under Grand PE474/7-1/2) as part of the PANDOWAE project. Reviewers' and editor's valuable comments are appreciated.

Open Access This article is distributed under the terms of the Creative Commons Attribution 4.0 International License (http://creativecommons.org/licenses/by/4.0/), which permits unrestricted use, distribution, and reproduction in any medium, provided you give appropriate credit to the original author(s) and the source, provide a link to the Creative Commons license, and indicate if changes were made.

\section{References}

Blender R, Fraedrich K, Lunkeit F (1997) Identification of cyclone-track regimes in the North Atlantic. Q J R Meteorol Soc 123:727-741

Bond G, Showers W, Cheseby M, Lotti R, Almasi P, deMenocal P, Priore P, Cullen H, Hajdas I, Bonani G (1997) A pervasive millennial-scale cycle in North Atlantic holocene and glacial climates. Science 278:1257-1266

Bordi I, Sutera A (2001) Fifty years of precipitation: some spatially remote teleconnections. Water Resour Manag 15:247-280

Bordi I, Fraedrich K, Petitta M, Sutera A (2006) Large-scale assessment of drought variability based on NCEP-NCAR and ERA-40 re-analyses. Water Resour Manag 20:899-915

Bothe O, Fraedrich K, Zhu XH (2010) The large-scale circulations and summer drought and wetness on the tibetan plateau. Int $\mathrm{J}$ Climatol 30:844-855

Chen F, Huang X, Zhang J, Holmes JA, Chen J (2006a) Humid little ice age in arid central Asia documented by Bosten Lake, Xinjiang, China. Sci China Ser D 49(12):1280-1290

Chen YN, Takeuchi K, Xu CC, Chen YP, Xu ZX (2006b) Regional climate change and its effects on river runoff in the Tarim Basin, China. Hydrol Process 20:2207-2216

Chen X, Wu JL, Hu Q (2008) Simulation of climate change impacts on streamflow in the Bosten Lake Basin using an artificial neural network model. J Hydrol Eng 13:180-183

Conversi A, Fonda Umani S, Peluso T, Molinero JC, Santojanni A et al (2010) The mediterranean sea regime shift at the end of the 1980s, and intriguing parallelisms with other European Basins. Plos One 5(5):e10633. doi:10.1371/journal.pone.0010633

Diffenbaugh NS, Scherer M, Ashfaq M (2013) Response of snowdependent hydrologic extremes to continued global warming. Nat Clim Chang 3:379-384

Ding Q, Wang B (2005) Circumglobal teleconnection in the Northern Hemisphere Summer. J Clim 18:3483-3505

Ertel H (1942) Ein neuer hydrodynamischer Wirbelsatz. Meteorol. Z. 59:277-281

Fraedrich K (1994) An ENSO impact on Europe? Tellus 46A:541-552

Hagemann S, Arpe K, Bengtsson L (2005) Validation of the hydrological cycle of ERA40. Reports on Earth System Science 10. Max Planck Institute for Meteorology, Hamburg 
He H, Lu GH (2013) Precipitation recycling in Tarim river basin. J Hydrol Eng 18(11):1549-1556

Hellström C (2005) Atmospheric conditions during extreme and nonextreme precipitation events in Sweden. Int J Climat 25:631-648

Hoskins BJ, McIntyre ME, Robertson AW (1985) On the use and significance of isentropic potential vorticity maps. Q J R Meteorol Soc 111:877-946

Kingston DG, McGregor GR, Hannah DM, Lawler DM (2007) Largescale climatic controls on New England river Flow. J Hydrometeorol 8:367-379

Lau K-M, Weng H (2002) Recurrent teleconnection patterns linking summertime precipitation variability over East-Asia and North America. J Meteorol Jap 80:1309-1324

Mannig B, Müller M, Starke E, Merkenschlager C, Mao W, Zhi X, Podzun R, Jacob D, Paeth H (2013) Dynamical downscaling of climate change in Central Asia. Glob Planet Chang 110:26-39

Plumb RA (1985) On the three-dimensional propagation of stationary waves. J Atmos Sci 42:217-229

Takaya K, Nakamura H (1997) A formulation of a wave-activity flux for stationary Rossby waves on a zonally varying basic flow. Geophys Res Lett 24:2985-2988

Talaee PH, Tabari H, Ardakani SS (2014) Hydrological drought in the west of Iran and possible association with large-scale atmospheric circulation patterns. Hydrol Process 28:764-773

Tao H, Gemmer M, Bai YG, Su BD, Mao WY (2011) Trends of streamflow in the Tarim River Basin during the past fifty years: human impact or climate change? J Hydrol 400:1-9

Tao H, Borth H, Fraedrich K, Schneidereit A, Zhu X (2015) Hydrological extremes in the Aksu-Tarim River Basin: Climatology and regime shift. Clim Dyn. doi:10.1007/s00382-015-2649-3

Uppala SM et al (2006) The ERA-40 re-analysis. Q J R Meteorol Soc 131:2961-3012
Wallace JM, Gutzler DS (1981) Teleconnections in the geopotential height field during the Northern Hemisphere Winter. Mon Weather Rev 109:784-812

Wang HJ, Chen YN, Li WH (2014) Hydrological extreme variability in the headwater of Tarim River: links with atmospheric teleconnection and regional climate. Stoch Environ Res Risk Assess 28:443-453

Wei J, Zhang QY, Tao SY (2003) Characteristics of atmospheric circulation anomalies during persistent droughts in North China for last two decades. J Appl Meteorol 14(2):140-151

Wu YP, Shen YP, Li BL (2012) Possible physical mechanism of water transport over Tarim Basin. Ecol Complex 9:63-70

Zhang XD, He JX, Zhang J, Polyakov I, Gerdes R, Inoue J, Wu PL (2013) Enhanced poleward moisture transport and amplified northern high-latitude wetting trend. Nat Clim Chang 3:47-51

Zhang L, Zhu XH, Fraedrich K, Sielmann F, Zhi XF (2014a) Interdecadal variability of winter precipitation in Southeast China. Clim Dyn. doi:10.1007/s00382-014-2048-1

Zhang L, Zhu XH, Fraedrich K, Sielmann F, Zhi XF (2014b) Interannual variability of winter precipitation in Southeast China. Theor Appl Climatol. doi:10.1007/s00704-014-1111-5

Zhao BK, Cai CX, Yang LM, Wang H (2006) Atmospheric circulation anomalies during wetting summer over Xinjiang region. J Glaciol Geocryol 28(3):434-442 (in Chinese)

Zhao K, Li X, Dodson J, Atahan P, Zhou X, Bertuch F (2012) Climatic variations over the last $4000 \mathrm{cal} \mathrm{yr} \mathrm{BP}$ in the western margin of the Tarim Basin, Xinjiang, reconstructed from pollen data. Palaeogeogr Palaeoclimatol Palaeoecol 321-322:16-23

Zhu X, Bothe O, Fraedrich K (2011) Summer atmospheric bridging between Europe and East Asia: influences on drought and wetness on the Tibetan Plateau. Quat Int 236(1):151-157 